\title{
GANGGALI GARRAL DJUYALGU (WEAVING STORY): INDIGENOUS LANGUAGE RESEARCH, THE INSIDER-OUTSIDER EXPERIENCE AND WEAVING ABORIGINAL WAYS OF KNOWING, BEING AND DOING INTO ACADEMIA
}

\author{
Anjilkurri Radley 1 \\ Western Sydney University \\ Tess Ryan \\ Australian Catholic University \\ Kylie Dowse \\ Melbourne University
}

\begin{abstract}
Aboriginal weaving is used as a method to explore new understandings and extend on the notions of insider-outsider in the research space. Just as weaving requires different strands of fibres, the insider-outsider researcher finds ways to enable the co-existence of differing authorities, roles, and responsibilities as community Elder and emerging researcher alongside the development of culturally resonant research approaches and methodologies.
\end{abstract}

This paper weaves together strands that are a representation of Aboriginal knowing, being, and doing: cultural practices that influence Indigenous language revitalisation research. As an Indigenous Australian researcher, community Elder, language teacher and activist, the lead author Radley is experienced in the complexity of performing multiple roles while undertaking research. She relays the tensions inherent in an insideroutsider researcher identity through her research into the revitalised Gathang language (Mid North Coast, New South Wales, Australia). Aboriginal academics, co-authors Ryan and Dowse explore Indigenising academic spaces, the politics of elevating Aboriginal protocols to transform research ethics, and the importance of listening and telling our stories in our own ways. Together, the authors interweave their stories to demonstrate partnerships between research and culture and speak of the importance of Indigenising the academy.

Keywords: Aboriginal researcher, language revitalisation, weaving story, insideroutsider, ethics processes

Citation: Radley, A., Ryan, T., and Dowse, K. (2021). Ganggali Garral Djuyalgu (Weaving Story): Indigenous language research, the insider-outsider experience and weaving

\footnotetext{
${ }^{1}$ Correspondence: Anjilkurri Radley, Western Sydney University, anjilkurriconnections@hotmail.com
} 
Aboriginal ways of knowing, being, and doing into academia. WINHEC: International Journal of Indigenous Education Scholarship, 16(1), pp. 411-448.

http://dx.doi.org/10.18357/wj1202120293. Special Issue on Indigenous Language Revitalization: Innovation, Reflection and Future Directions, Guest Co-Editors Drs. Onowa McIvor and Kari A. B. Chew. 


\section{Minya Djuyal (This is The Story)}

Djiyagan (sisters) are moving grasses in a free weave motion, meaning there is no set pattern. Grasses can be woven vertically, horizontally or diagonally to fill the spaces to create butjin (basket). Thus, we are telling our stories in ways that go beyond the expected academic writing formulations to capture the interconnectedness that exists within each story. We interweave our stories, at times in the first person, interspersed with academic writing and Gathang language to communicate to the readers the making of something new in a style that is our own.

\section{Figure 1}

Sisters Weaving Stories

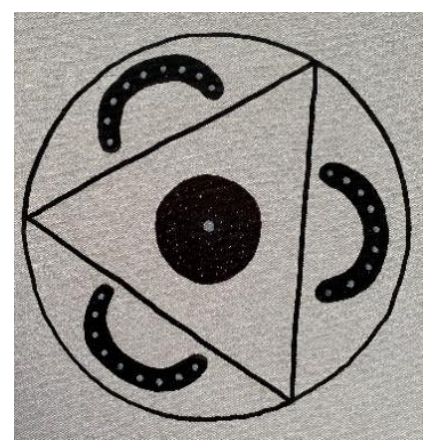

Note: Artwork and story by Anjilkurri Radley: outside circle: the connection to Mother Earth; semi-circles: sisters sitting; small circles: contributions made from the heart; central circle: creation; triangle: transformation.

Aboriginal people from (what is also known as) New South Wales (NSW), Australia have been weaving for tens of thousands of years, or as we prefer, since time began. Weaving provides a resonant structure for storytelling. Story is a key essence of what Martin and Mirraboopa (2003, p. 208) have referred to as our ways of "knowing, being, and doing." It has given us abilities to relate, connect, and understand as well as view our world 
through a lens that is our own. Story is interwoven into the fabric of our lives. Drawing on weaving as a method to express our stories aligns with cultural practices that see our women sitting in circle weaving and djuyaliyn (talking) (see Figure 1). We describe weaving as method and cultural process as our individual strands weave together with collective ways of knowing, being, and doing openly and freely. We extend on Chew's (2019) metaphor of weaving as cultural practice to convey a model for planning and decision making that acknowledges ancestral wisdom. Weaving is an intangible knowledge process, narrative, belonging, and knowledge transference. This is beyond metaphor, as metaphor ${ }^{2}$ suggests our ways are less legitimate than theory or method. It is conceptual framework building in its most resonant form.

As we djiyagan visualise strands of grasses coming together, our stories interconnect to construct butjin (basket), which carries our hopes for transforming the academic system. Butjin (basket) holds Aboriginal cultural ways of knowing, being, and doing the space to explore the insider-outsider notion (Smith, 2012); provides insights into what is needed to support Aboriginal researchers to achieve their goals; and gives voice to the importance of honouring Aboriginal protocols alongside the academy's ethics processes within the context of language revitalisation research.

The three Aboriginal women researchers who are weaving and storytelling are Anjilkurri Rhonda Radley, Tess Ryan, and Kylie Dowse. Anjilkurri Rhonda Radley is a proud Goori ${ }^{3}$

\footnotetext{
2 Tuck, E. \& Yang, K. W. (2012). Decolonization is not a metaphor: Decolonization: Indigeneity, Education \& Society, 1(1), 1-40.

3 This article uses various terminology interchangeably to discuss Australia's First Peoples such as Aboriginal, Torres Strait Islander, Indigenous, Black, and Goori.
} 
woman with strong cultural and family ties to the Birrbay and Dhanggati peoples (Mid North Coast region, NSW, Australia) through bloodlines of grandparents Guula, William Henry Holten (nee Davis) and Josephine Pearl Moran. Acknowledging grandparents enables other Aboriginal people to position Anjilkurri within their kinship structure. Tess is a Birrbay woman and academic whose research focuses on Aboriginal and Torres Strait Islander women, leadership, representation, and support of students. Tess is part of Anjilkurri's PhD supervisory team. Kylie is a Gamilaraay woman with ties to Bundjalung nation, living on Birrbay country, whose community practice, teaching, and research focus on strengthening Aboriginal-led solutions to problems resulting from colonisation.

Each djiyagan brings unique strands of experience into the weave and through these strands, we demonstrate the myriad of discussions required to navigate both the research paradigm and the richness of cultural values and protocols. In a time when Indigenous knowledge is recognised within the university system in Australia, many important conversations are required around homogenising mindsets inherent in the ethics process. Elder knowledge and practice is the significant driving focus of our identity and knowledge building. Their wisdom enacts in us the power to see knowledge as interconnected, therefore allowing our research to have a resonance beyond dominant Western scholarship. Privileging the multi-layered insider and outsider perspectives brought by Indigenous researchers can inform and challenge research processes.

The ways cultural protocols, personal ethics, and university ethics processes interact offer opportunities to broaden the common area between each while keeping people safe in research. In this paper, we will, therefore, draw from Nakata (2017) and refer to the overlapping realm as "cultural interface." How we align personal ethics with research is 
evident in our using accessible language to value our readers beyond urges to "sound clever" or somehow prove we belong in academia. Sharing stories to enrich understandings of what we have experienced and why we have made particular decisions in relation to research brings Aboriginal ways of knowing, being, and doing to the research space (Tachine, 2018). We resist deficit-based storying of our people and take note of Senior Kaurna Elder Aunty Barb Wingard's call for "telling stories in ways that make us stronger" (Wingard \& Lester, 2001, p. 1). Anjilkurri, community Elder/emerging researcher, takes the lead in weaving story.

\section{Yukulduwa Ganggali Garral (Weaving Through the Heart)}

Anjilkurri: The weaving of a solid base for butjin (see Figure 2) is crucial in supporting the structural design of a carry vessel. As Baan (Aunty and Elder), I start the weave with telling my story of educational challenges, disconnection, and connection to language and language revitalisation research. I construct a context to generate dialogue for djiyagan to contribute. In weaving their strands of grass, telling their stories, butjin grows in capacity and strength to connect us, our stories, and inform a way forward. 


\section{Figure 2}

Weaving Through the Heart

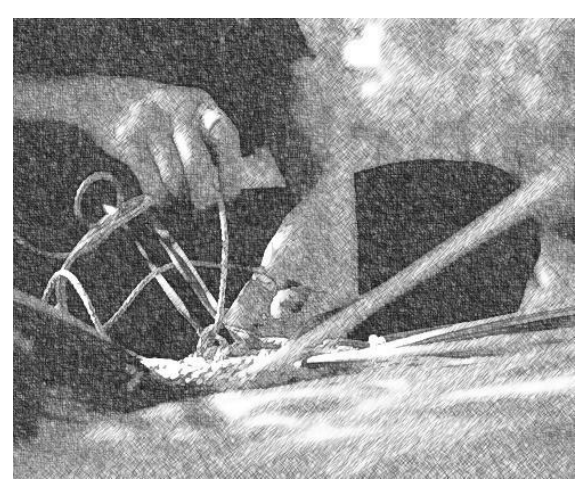

Note: Photograph by Arlene Maree, image produced by Anjilkurri Radley

In telling my story I share from the heart the journey of ngarrayn (learning) to give a contextual narrative and an insight to my cultural standpoint. I left school at 15 to financially contribute to my family's household. I had the chance to go back to school for a period at 17. I resumed school with a different outlook on life; I found other students unappreciative and immature in their attitude towards their education and others. I had to leave school again due to becoming pregnant with the first of my four daughters. Upon reflection, I loved learning but found the education system to be biased, judgemental, and with no Aboriginal content. In the 1970s there was no truthful mention of Aboriginal peoples' history or culture. This experience inspired me to want to work within the education system and support Aboriginal students in their understanding of their history, culture, and identity.

As a mature student, I commenced education at university completing a Bachelor of Teaching, Graduate Diploma in Education, then later obtained a Master of Indigenous Languages Education (Hobson et al., 2018). Past experiences enabled me to relate to students who were struggling in their learning and to subsequently develop learning 
experiences that engaged students beyond the classroom. My teaching philosophy is based on traditional Aboriginal ways of learning. This involves bringing story to life through storytelling, movement, song, dance, the use of symbolism, and connection to land, ancestors, and community.

For many years I have worked in and across Aboriginal organisations, government and non-government organisations, and education systems to give voice to and respond to the needs of Aboriginal people. Over time I became disheartened in the lack of change within the colonised systems and decided to shift my focus to community capacity building. Language revival and working with Aboriginal women promised a way forward.

In this paper, I will reflect on my upbringing where strong aunties, mothers, and grandmothers modelled caring for others, a pride in their culture, and a desire for the next generation to do well. These women experienced the full force of government policies: welfare intervention, separation from family, and other forms of racism. On behalf of those women, I am working to create change, and I am using Gathang language as an instrument to drive that change.

\section{Wiyagi Gathang (A Call to Language)}

Anjilkurri: In wuruma (the wind), language moves through the trees, awakens the people, changes landforms, and sings up the ancestors. Speaking the language of the land connects me to my culture, mob, land, and ancestors. The language of the land was never forgotten; it lived within the land and all she holds. 


\section{Figure 3}

Wuruma Moving Through the Trees

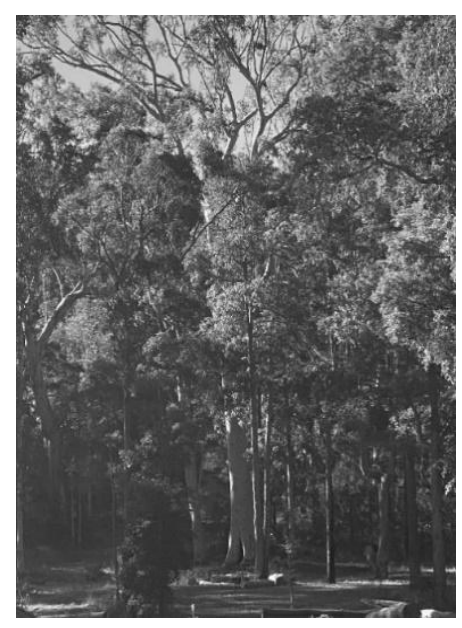

Note: Photograph by Anjilkurri Radley

The disruption of our language and culture being passed down from generation to generation is a product of colonisation. In the colonising process, foreign laws and policies were introduced to enable the forced removal of Aboriginal people from their ancestral lands and the separation of children from their families and culture. As the late Yankunytjatjara Elder Uncle Bob Randall discussed in the documentary film The Land Owns Us, the responsibility to revive and fortify cultural aspects such as language is still ever-present. That connectedness, Uncle Bob said, "to care for my country, care for my mother, care for everything around me ... the oneness ... the completeness of that oneness ... [we] call it Kanyini" (Randall, 2006, 3:47). Growing up carried a strong sense of family and connection to land, yet I felt deep within my spirit a link to culture was missing. Our family shared language words interspersed in English, but I craved the fluency of the language of my ancestors. After the release of the Gathang dictionary (Lissarrague, 2010), I learnt Gathang language alongside other family members. I then 
continued with further studies to become a language teacher and activist. The Gathang language is spoken by Birrbay, Warrimay, and Guringay people located along the east coast of NSW, Australia. Gathang was one of 35 Aboriginal languages spoken in NSW prior to British invasion. Over time English became the spoken language, with Aboriginal people forbidden from speaking their native tongue (Lissarrague, 2010).

Working in partnership with Muurrbay Aboriginal Cultural and Language Cooperative (Ash et al., 2010) and the Gathang Language Group, I started to become active in reviving the Gathang language. Without fluent speakers and little audio recorded language to draw upon, bringing back language that had been bubaliyn (sleeping) seemed almost an impossible task. After years of teaching language, listening now to our language being presented in song, dance, signage, and everyday talk brings pride in the fact I have had a strong influence in making this possible.

I am a community Elder, a title that is earned through sustained leadership, involvement, and dedication to community and accepted knowing and understanding its responsibilities and obligations. Eldership elevates status in community and requires availability. There is an opportunity here, within this role, for me to do more work in bringing Aboriginal language to the hearts and minds of all communities. I wanted to contribute to the efforts being made to revitalise Aboriginal languages in Australia.

\section{Matjarr Djuyal (Hand Talk)}

Anjilkurri: The hands are used with language to tell the story of "Bila Yii Maraliyn." Mitji Djiyagan (Little Sisters) sing in language, their hands moving fluidly to convey the motion of the flowing river (see Figure 4). 


\section{Figure 4}

The River is Flowing

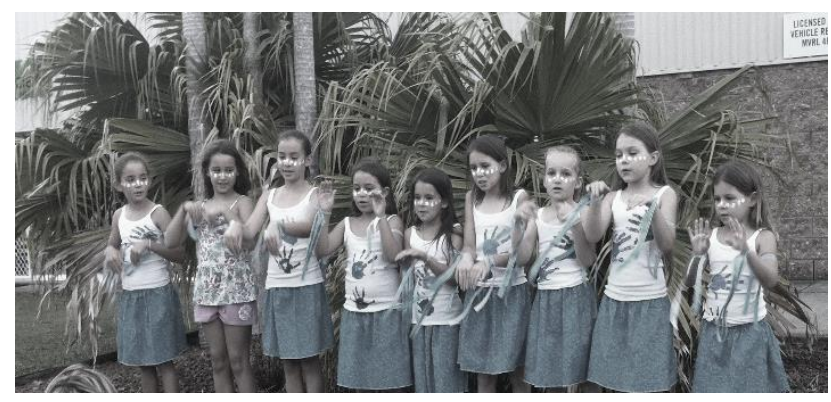

Note: Photograph by Anjilkurri Radley

In teaching the Gathang language I continually used gesture, bodily movements to transmit information. Gesture has long been part of traditional Aboriginal teaching methods to convey the meaning of spoken words (Power, 2013). For example, a movement of hand towards self directs a person to come, or in storytelling, all-body movements can be used to enhance the meaning of the story. I wanted to formally explore the effectiveness of gesture to learn the Gathang language. ${ }^{4}$ Current research in language teaching and human cognition provides evidence to suggest that gesture may facilitate the acquisition of a second (spoken) language by adults and children (Goldin-Meadow, 2014; Gullerg, 2014; Macedonia \& Von Kriegstein, 2012). Although gesture has long been part of the communicative repertoire of Aboriginal languages, there is an absence of research examining the efficacy of gesture in facilitating the acquisition of Aboriginal languages in a revitalisation setting led by an Aboriginal researcher.

\footnotetext{
${ }^{4}$ See Radley, A., Jones, C., Hanham, J., \& Richards, M. (2021) Matjarr Djuyal: How using gesture in teaching the Gathang helps preschoolers learn nouns. Languages, 6(2) 103.

https://doi.org/10.3390/languages6020103
} 
The decision to undertake formal research in the use of gesture to learn the Gathang language came with some trepidation of stepping into the unknown. How would my community who knew me in the role of Elder and teacher view me as an emerging researcher ${ }^{5}$ How can I use my cultural standpoint to elevate Aboriginal ways of thinking and doing? These questions could only be answered by engaging with my nature of knowing through the research journey with an intention similar to that described in the work of Margaret Kovach, "expression of the relevant narrative from personal experiences, those reminiscences of life rooted in our earliest experience that shape our understanding of the world" (Kovach, 2009, p. 112).

Guided by Caroline Jones, my PhD principal supervisor at Western Sydney University, I explored the possibilities of my research framework to incorporate the use of my cultural standpoint, intrinsic to my ways of knowing. Thus with my ancestors, I stepped into the unknown.

5 The term "emerging researcher" is preferred as it better aligns with concurrent Eldership role than "student" or "junior" researcher. 


\section{Ngarralbaa (Learning Place)}

Anjilkurri: As I walked over barray (the land) my understandings of relatedness guided me on, the journey of exploring an untrodden path, developing a framework for language research. In that moment I acknowledged that all things are connected and what I perceive as not knowing is only a lack of connectedness.

A native flower, the small bush iris, appeared when I was contemplating the importance of this research to my community. This flower image informed the design of the research framework. The flower's three petals reflect ways of approaching the research and represent the "knowledge" element, the "experiential" element, and the "cultural" element (see Figure 5). These elements are pivotal in the research design and the creation of new knowledge for the language research. The research design consists of guiding questions that are central to the collection and analysis data. This will ascertain the extent of new knowledge that will be acquired from the research. Although there is literature outlining a variety of research, theories, and approaches to support the research, it is the cultural practices that will influence how the research is undertaken and how information is correlated and presented. 


\section{Figure 5}

Research Framework Elements

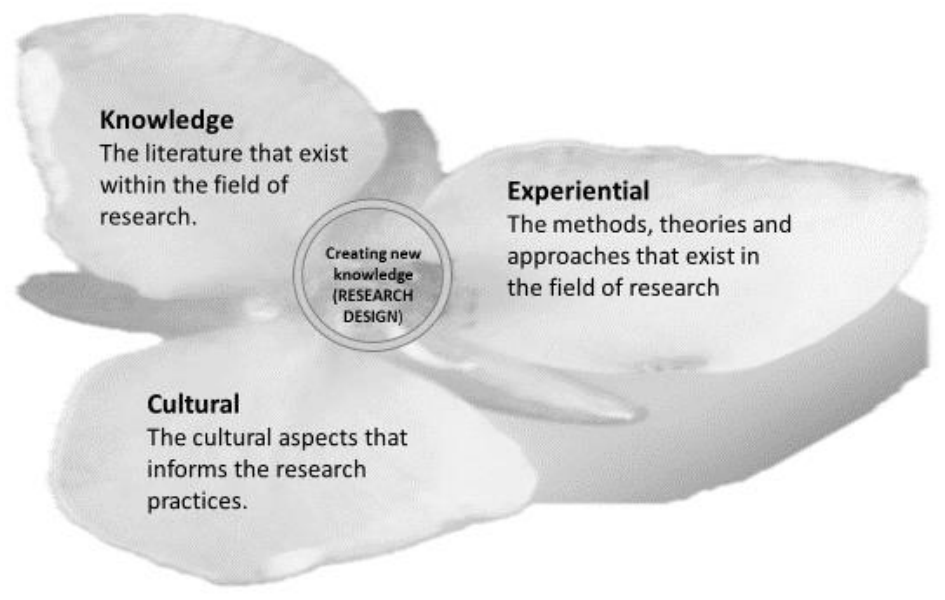

Note: Image produced by Anjilkurri Radley

This approach gives equal importance to the ethical processes and Aboriginal community protocols and embeds the cultural element within the development of the methodology for the research. It was inspired by Indigenous researchers such as Smith (2012) and Yunkaporta (2009). Working within a methodology framework that instils cultural respect to guide the research approach originates models for other emerging Aboriginal researches to consider. This supports the position that other Indigenous scholars have proclaimed. Wilson (2008, p. 54) states, "Indigenous scholars are in the process of shaping, redefining and explaining their positions. They are defining the research, outlining the ethical protocols and explaining the culturally congruent methodologies that can be used at the behest of their communities."

University ethics processes and cultural protocols/practices lay the ground work to engage with the emerging Aboriginal researcher's standpoint (Wilson, 2008, p. 11). University ethics processes generally require emerging researchers to think through and 
plan for possible harms for people engaged in research. A specific form is completed then submitted to a university ethics committee for approval. Processes vary across universities; however, there is consensus that research engaging Aboriginal people attracts greater scrutiny. Cultural protocol is a broad term to describe intricate codes for behaviour and interaction among Indigenous peoples, lands, and waters. Protocols vary across countries and mobs (nations and clan groups) with a consistent thread of respect woven through. In order to understand cultural considerations, further the validity of the Aboriginal researcher and community Elder, cultural standpoint (cultural practice) that integrates ngarrangga (must listen) is explored.

\section{Ngarrangga: A Cultural Practice of Listening}

Through the years we have listened to the stories. In the Aboriginal way, we learn to listen from our earliest days. We could not live good and useful lives unless we listened. This was the normal way for us to learn-not by asking questions. We learnt by watching and listening, waiting and then acting. (Ungunmerr-Baumann, 1993, p. 35)

As an Aboriginal researcher and community Elder, my cultural standpoint is the embodiment of my nature of knowing, being, and doing. This is induced by ngarrangga, an important cultural practice. Within deep listening there is a connection to self, others, ancestors, and the oneness of all there is. A place of listening beyond the ears is encapsulated within all senses and brings us into the present. It gives us guidance through a knowing that forges a path to behave in a respectful way. Once you know it you cannot unknow it-it simply is. 
Further evidence supporting ngarrangga is beginning to be written about in academic spheres. Senior Elder Miriam-Rose Ungunmerr-Baumann reflects on such principles described in her language Ngan'gityemerri as dadirri (deep listening). She says, "Dadirri is inner, deep listening and quiet, still awareness. Dadirri recognises the deep spring that is inside us. We call on it and it calls to us" (Ungunmer-Baumann, 1988, p. 9). Ngarrangga holds value for research projects in enhancing our ability as researchers to listen to more than spoken or recorded words, instead urging us to seek understanding more fully.

Yunkaporta's thesis captures some of the general principles in Indigenous ethics research processes that are evident in my cultural standpoint: "As respecting the living and culturally managed nature of knowledge, being present, listening deeply, learning and enriching community learning, being real, respecting all things, engaging in relations (cultural, environmental, historic and social), and understanding that while these principles may be generalisable, methods arising from them in a particular community are not" (Yunkaporta 2009, p. 8). To maintain the integrity of my cultural standpoint within the context of this research is to listen deeply, act respectfully, ensure ethics and protocols processes are woven into research methodologies, ensure accountability, and establish culturally safe practices. The interweaving of cultural values and protocols with academic ethics benefits both researchers and the researched (Nakata, 2017) Nyiirun ngarrangga (we all must listen).

\section{Djinangga Yuungga (Insider-Outsider)}

My cultural standpoint shapes the way I interact with all research stakeholders: people who have a vested interest in or may be affected by the research. Stakeholders include the academy, language learners, parents, community preschool staff, all local community 
members, and language cohorts. My cultural standpoint influences positionality and relatedness to the insider-outsider notion. The insider-outsider notion is a concept of positioning oneself within the realms of research investigation. Researchers over the years have had ways of exploring and defining this notion: "Whether the researcher is an insider, sharing the characteristic, role, or experience under study with the participants, or an outsider to the commonality shared by participants, the personhood of the researcher, including her or his membership status in relation to those participating in the research, is an essential and ever-present aspect of the investigation" (Dwyer \& Buckle, 2009, p. 55).

It is suggested that Evered and Louis presented the terms "inquiry from the inside and inquiry from the outside" (1981, p. 385). Understandings of insider-outsider research are critical in the research process, and within this concept issues relating to subjective positioning and a privileging of identity must be explored.

Insider and outsider, or "emic and etic" (Pike, 1954, p. 37) labels in research initially related to the potential for scientific bias. There was little appreciation for insider qualitative research, and findings were considered questionable and lacking in objectivity. The work of Barbara Myerhoff, a Jewish-American filmmaker and anthropologist in the 1970 s and 1980s shifted her research lens from examining "exoticised others" to focusing her research on projects involving and benefitting ageing Jewish women (Myerhoff, 2007). Myerhoff's approach placed value on nuanced understanding of research as storytelling in and of one's own culture. 
Other key advantages to being a research insider are described by Bonner and Tolhurst (2004) as holding a greater understanding of the specific culture studied, keeping a flow between the social interaction of the researcher and respondent, and having an existing or established level of intimacy promoting truth-telling within the research process. We are meant to understand the political intersections between who we are as a collective, and what we conclude of the world around us. The dichotomy that exists within insider research is that of collective and familiar knowing and that of individual perspectives.

Karen Martin investigated the ways Rainforest Aboriginal people regulate outsiders and the implication for Western research and researchers in her doctoral thesis and book, Please Knock Before You Enter (2008). Martin located through the Burngu, Kuku-Yalanji community, three types of relatedness in Indigenous research: "Ngarrbal (stranger who is not known), waybak (whiteman who is known about), and jarwon (friend who is known)" (Martin, 2008, p. 5). This relatedness situates understandings of insideroutsider research from multiple perspectives.

These researchers identify that relatedness to the culture studied and the establishment of relationships determines your position as an insider and/or outsider. I consider myself predominantly an insider, conscious of the impact my role as researcher may have on my relationship with language learners, family, and community, knowing I will have to deal with the consequences of my behaviours and processes (Smith, 2012).

Multiplicity exists within my roles in the context of the research undertaken in my local community. I am a board director for the community preschool where the study is situated, deliver language lessons to the learner cohorts, and conduct testing for 
individual results. I have long-standing membership in all nine organisations that supplied support letters to my university's ethics committee for the research. I am a language activist, teacher and learner, Aboriginal Elder, and researcher. I navigate these roles freely and respectfully, as I am conscious of the privileges they afford in my community and research investigation.

As an emerging researcher coming from an insider position of Eldership and Traditional Owner within my community, in the world of academia I was, as Martin (2006) described, "[a] stranger who is not known" (p. 5). Although Martin refers to this within a nonIndigenous context, I perceived myself as the same in the academy, an outsider, an unknown stranger grappling with the lack of status, authority, and connection.

The motivation to persist with research despite uncertainty is found among language learners, family, and community and knowing language research is both an act of decolonisation and a means to revive language as cultural practice. Within the notion of cultural insider connecting to the academy as an outsider, I developed a broad lens to visualise what was needed to support the continuance of my research journey and to develop ideologies to Indigenise the academy. I recognised I was conceding my cultural standpoint when engaging with my non-Aboriginal research supervision team due to my inability to articulate the dilemma of where to position my being within the academy. I struggled initially to find the common ground, the cultural interface, a cultural meeting place where my supervision team and I could converse in greater depth about my research. I considered what further support mechanisms were required. Support materialised in the form of two Aboriginal researchers, sisters Tess and Kylie. 


\section{Djiyagan Djuyaliyn Djuyal (Sisters Telling Stories)}

As I stop weaving into the butjin, the storytelling of my research experiences brings our djiyagan circle into ngarrangga, a place to reflect. To continue the weave, djiyagan share their connection to me, a community Elder and emerging researcher. Their strands of grass find their place to shape butjin, as their stories find their place within my story to strengthen its capacity.

\section{Wubal Matjarru Djinanggabirang (Weaving from the Inside)}

Djiyagan, Tess is my mentor and a member on my supervision panel. As an emerging researcher, I am grateful to Tess for accepting my invitation to join my supervision panel. At a university session I attended, Tess spoke these words: “The term 'decolonising' is used regularly in discussions around disrupting the institution, yet I am unsure whether we can do that to its fullest extent. So realigning, resetting, and re-empowering our Black bodies through a Western system of knowledge production is how I name what I attempt to do within academic institutions" (personal communication, July 20, 2019).

Anjilkurri: In this moment I had a knowing Tess would be instrumental in my growth as an emerging Aboriginal researcher. Throughout our many conversations Tess conveys her understanding of her positionality within the insider-outsider notion in multiple domains. She gives insights into the level of support required for Aboriginal researchers to reach their goals and the value of listening. Tess empathises with the complexity of amalgamating Aboriginal epistemology within the academy. Weaving story with Tess has enabled two Birrbay sisters to connect and share the importance of language and culture to identity. 
Baan Anjilkurri and I met through a research capability building program I was presenting in. It is there that she asked for me to join her on her research journey. The pathways that lead us often appear stronger in hindsight, yet my reflections of our connection had a resonance to it I will always remember. It is through our connection that a strong sense of culture exists. Nakata's "cultural interface" demonstrates this meeting in those middle spaces where the shared moments of knowing and not knowing create learning and purpose. The engagement between those middle spaces builds in us both deeper philosophical arguments and understandings within the "corpus of knowledge" that is Indigeneity (Nakata, 2017, p. 350).

The dislocation from my country and cultural teachings has motivated my educational career to building an awakening of what was bubaliyn and of learning within the Western models of the education system. Baan is sharing the knowledge of reviving Gathang language, and through that knowledge sharing process, my cultural values are further broadened, as is my sense of belonging and identity. The language of Birrbay culture and those cultural embers live inside the body, consisting of values, protocols, language, and being. Organically it has slept within and showed brief moments of ignition, yet with this shared engagement between Elder knowledge and academic knowledge, that being is now burning strongly between us.

I also understand what it feels like as an Indigenous student within a structure that regularly seems to want us for our knowledge yet wants to also shape us through the prism of their own. Previous research undertaken with regards to the Indigenous health researcher workforce demonstrated how integral "peer generative power" was in the context of Indigenous research training (Ewen et al., 2019, p. 8). Through the sharing of 
experiences, the alignment of knowledge, and the challenges faced in approaching Western knowledge structures, a large degree of shared guidance and support is offered within the cohort of students on the PhD journey.

There is immense need for levels of support for Indigenous students, and institutions have been acutely aware of this. These levels of support include Indigenous student centres, writing retreats, and research capacity building programs, which develop higher degree research aspirations (Asma \& Page, 2011). Yet one of the failings in the attempt to form structures to support students is the recognition of the legitimate power generated through the shared and collaborative pathways these students create. True also is that the value of Black women in spaces of knowledge within the academy has been accepted without recognition of the gift that sharing brings to the academy itself (Fredericks et al., 2014). Baan felt through witnessing me sharing my knowledge that having me on her PhD team gave her what was missing-being someone who was within the realms of being "inside her inside" (Black women together), as well as being "inside what was outside" (a knowing of the research space within the academy).

As an insider-outsider, I am regularly questioning my weaving (storytelling) through reflective practice. Where are the strands (stories) I carry and what weight do they hold for myself, my Blackness, and the legitimisation of my being within the academy? The greatest strand I bring to myself is that of power in my learnings as I awaken more language in myself to name all I have felt as an Aboriginal woman. For someone who sits neither firmly inside academic institutions nor outside of them, I have always considered myself dwelling on the edges of any parameter that tells me "I should" and rather focus on what I can discover and how it enriches me. 
My motivations push me to realign dominant Western systems to consider ways of being as Aboriginal and Torres Strait Islander people-that means different ideas and knowledge, which for many years has been undermined by the institutional structures we sit in. The work I do in supporting other students to build their understanding is paramount, and it is the power in how it is done that holds most value. Many younger or earlier students I speak to suggest that they are learning a new language within English language systems. When in deep conversation with others traversing educational spaces, I talk about nuances in disruption and an element of unlearning compliance to systems of knowledge while still in conversation with them. Ngarrangga has taught me to listen, observe deeply, and consider how we can speak our ways of knowledge so that it is at the forefront and not positioned as an afterthought within the academy. This is my construction of decolonising and can be considered as a point for further discussion. Henderson and Battiste (2000, p. 35) affirm that "Indigenous knowledge is not a uniform concept across all Indigenous peoples; it is a diverse body of knowledge that is spread throughout different peoples in many layers. Those who are possessors of this knowledge often cannot categorise it in Eurocentric thought, partly because the processes of categorisations are not part of Indigenous thought."

My interface with my Aboriginality is that of reclaiming what was removed by dislocation and trauma and therefore is personalised through those experiences (Ryan, 2019). Subjectivism suggests that social phenomena is created from perceptions and consequent actions (Beker et al., 2012). My drive to work in areas for change determines that future knowledge-building roles will be driven by my subjectivism. As I must observe a stance that embodies how I view knowledge, I therefore perceive my academic work to be focused on a sense of informing through investigation what must change for a better 
society. As neither fully inside nor outside the university, my pathway is firmly focused on the continuation of ngarraliyn (learning) that is of myself and how I assist in change for Aboriginal and Torres Strait Islander people. We all carry different strands of experience into our storytelling weave, and the acknowledgement of such is an integral element to the work of research.

\section{Wubal Matjarru Yuunggabirang (Weaving from the Outside)}

Djiyagan Kylie is my research mentor and a shining light in the darkness. As Kylie's Elder and Aunty, I am Kylie's cultural caretaker. I hold cultural authority, which I can and have evoked to influence decisions Kylie makes freely. While this might seem convoluted, it makes visible multiple parallel roles that we navigate seamlessly. Authority is understood in a different way to Western concepts of dominance, power, and hierarchy; instead it is lovingly enacted with respect, care, integrity, and connection. Our connection is strong. Through our connection, our weaving and storytelling highlights what is possible in honouring cultural protocols in academic research and ethics processes.

As I accept butjin to introduce new strands, flashes of memory spring to mind. I do not recall a first meeting with Baan Anjilkurri; instead, I accept knowing. Knowing describes cellular memory and acquired knowledge. Cellular memory is a complex phenomenon

which may be more clearly articulated through cultural storytelling practices. Archibald (2008, p. 83) refers to the diversity among "particular traditions, protocols, and rules concerning stories and the way the stories are to be told for teaching and learning purposes." Archibald (2008, p. 83) asserts our storying may "vary from the sacred to historical, from cultural traditions to personal life experiences and testimonials." The 
stories I share here sit somewhere between experience and testimonial, drawing on cyclic cultural practices of sharing my learning in order to teach ngarrangga.

We were sitting in powdery red dust under the dappled shade of mulga trees at women's camp near Uluru carving wati bunggil (clapsticks). Not having worked the tough, sunbaked branches of the mulga tree we had harvested, I began applying advanced shaping techniques without being shown. Strangely, I knew what to do as the wood sang to me, revealing its preferred shape as time melted away. Women began asking me how to work wati, their words and actions assuming the skill was a familiar one. Working wati with the ancient craft practiced by Aboriginal women for eons fused with my knowing, and I am grateful Baan Anjilkurri was present. Was this why she had brought me to this place of intense heat, swarming flies, and swag-sniffing dingoes? "When we get back home you can teach the other women," she said.

This conscious experience of ancestral memory underscores cultural protocols carried into my research through more intentionally trusting ancestors and their gifts of cellular memory to guide me when something is, or is not, right. The ethical processes and protocols are the pivotal aspects of Indigenous research, and as researchers we understand the responsibility placed on us to undertake research appropriately for our communities. 


\section{Figure 6}

Wati Bunggil (Clap sticks)

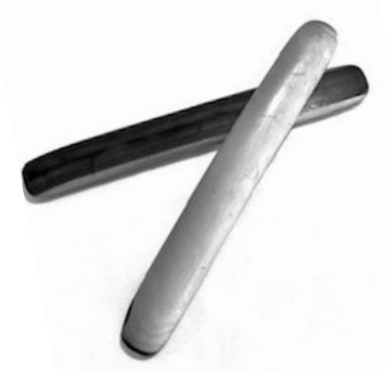

Note: Photograph by Kylie Dowse, hand-carved wati bunggil made with mulga sourced near Uluru on Anangu Country

This leads into another story more obviously related to my research. Cultural protocols surrounding Elders and their revered status in our world supported the identification of Western hierarchical positioning in relation to university research ethics. Too frequently, Aboriginal protocols and ways of knowing, being, and doing are reduced to esoteric "nice but unnecessary" permissions from reference groups, much like Acknowledgement of Country can be recited without understanding its meaning. It does not have to be this way. I have come to understand that researchers have the capacity to shape universities as knowledge is produced. Our work is political and does not require us to choose between culture and academic aspiration. Respectful, meaningful processes carved out through sustained team efforts can offer wonderfully resonant ways to collaborate. A robust pilot partnership between Birrbay people, my PhD supervisors and committee, and the University of Melbourne Ethics Committee provides an example of keeping 
people safe in research by honouring Aboriginal cultural protocols to enhance academic ethics processes.

\section{Saltwater Ngaluwi (Wave) Local Ethics Committee}

Gathered around a table in an overly air-conditioned hotel lobby in Hong Kong, Vanessa Davis, Anthony Newcastle, and I met with our PhD supervisors as a cohort. The cohort was a measured arrangement we negotiated to ensure adequate cultural and collegial support in our various research projects. We had graduated together as Masters of Narrative Therapy and Community Work and insisted on a formal Welcome to Country at the graduation ceremony where we, along with Justin Butler, collectively delivered the valedictorian speech. The graduation hall was made more elegant by Wurundjeri Elder Uncle Colin, who donned possum skin and ochre, and carried gum leaves to mark the occasion. As part of our cohort requirements, we selected our shared principal research supervisor, David Denborough, whose knowledge of Narrative Therapy and international Collective Narrative Practice we believed essential to support the integrity of our research (Denborough, 2008). It was David's suggestion that later led to Aunty Barb Wingard joining my supervisory team. Appreciation for this insight lingers.

I was explaining that a Birrbay community Elder, Baan "Aunty Rhonda" Anjilkurri, was invested in my community's research project and had ideas on how we might proceed. One of my supervisors (now enjoying well-deserved retirement while writing children's books) is highly experienced and cautioned that university ethics processes had not been followed in engaging with my community Elder "prematurely." By seeking Elder guidance ahead of university ethics committee approval, I could likely not write about our conversation in my thesis. Perplexed, I asked if the university had Aboriginal 
representation among those tasked with determining ethics applications. The answer brought a brief period of silence. "Not that I'm aware of." Being a bit cheeky by nature and feeling safe in the relationships built, I challenged this notion. "So, are you saying I'm supposed to seek permission from a group of non-Indigenous people to talk with my Elder?" My supervisor conceded it seemed bizarre when framed that way. It was a pivotal moment in my research journey, as I knew I could not progress until Aboriginal protocols received proper recognition.

As a team we worked through inverting cultural protocols and university ethics, formal and informal, big and small, each time correcting nuanced suggestions that the university was formal or big while the local committee was informal or somehow less substantial. Together, we arrived at a respectful arrangement of a Local Ethics Committee (Birrbay community members and other folks contributing their expertise, like community organisers dedicated to prison abolition) and a Faraway Ethics Committee (the university). A space for research was created where the Faraway Ethics Committee could not provide approval without first satisfying the Local Ethics Committee; however, the Local Ethics Committee could provide approval for processes affecting local community in isolation. Birrbay community retains rights to every word written. Baan Anjilkurri spoke by phone with my PhD committee chair, which honoured Anthony's suggestion that local mob and university folks converse. Both women were a little unnerved at first, each wanting to demonstrate respect, which was a fortuitous place to start. Aboriginal knowing, being, and doing became more fully acknowledged, and the research could progress. 
University ethics processes automatically flag Indigenous research projects as risky, and while the intention to protect is not without just cause, paternalism is evident in ways Aboriginal communities are excluded or relegated to tokenistic fringes of many research projects. Western research has led to damage-centred, deficit storying of how we experience Aboriginality (Tuck, 2009).

Stark insight into ways colonising approaches to education fail to appreciate cultural knowledges and render Aboriginal people as outsiders is provided in the documentary, In My Blood It Runs (Newell, 2020). The story relays an Aboriginal boy's experience of two worlds. In Aboriginal cultural ways, ten-year-old Dujuan Hoosan is positioned as capable, inheriting his grandfather's gift for healing sickness, which carries a position of great responsibility among his people. Simultaneously, Dujuan is depicted struggling at primary school while his teachers degrade Aboriginal spirituality and question his behaviour and frequent absence from the school. Footage shows Dujuan's joyful engagement with weekly Arrente language classes; the contrast in his participation and interest is striking. A community change project springs from the film, calling for Arrenteled schools.

Much like Dujuan, Indigenous researchers walk in two worlds. The notion of Aboriginalled universities seems a too-distant concept for many of us presently engaged in research and academic pursuit. Concurrent to the work of those pursuing enormous change, we can work productively with universities to change existing structures and approaches within them. While I acknowledge it is not the same for all, my experience has been overwhelmingly positive, with university folks surrounding Saltwater Ngaluwi equally enthusiastic about changes we have made together. 


\section{Wakulda Yabang Mayan.gu (A Way Forward as One)}

We djiyagan have woven our stands of grasses from the inside and from the outside to tell our stories in our own ways to give meaning to our positioning within the weaving circle. As we continue to weave together the last strands of grasses into butjin, our storytelling focuses on the connections as a way forward to bring oneness, wakulda (as one) to the academy.

The article has applied a unique method of free weave storytelling, sisters sitting in circle, sharing cultural and academic knowledge and experiences. The storytelling demonstrates the need for purposeful conversation and action regarding university ethics and cultural protocols and to include greater support for emerging Indigenous researchers. Wilson (2008, p. 54) states,

Indigenous scholars are in the process of shaping, redefining and explaining their positions. They are defining the research, outlining the ethical protocols and explaining the culturally congruent methodologies that can be used at the behest of their communities.

We call on universities and emerging Indigenous researchers to view university ethics processes as opportunities to broaden, document, and formalise the cultural interface. Ngarrangga; engaging with nation and clan cultural protocols; and seeking advice ahead of approval from Aboriginal Elders, communities, and mentors are all ways to support robust research while mitigating risk.

We invite universities to critically examine how ethics processes and committees are structured and their positionality in relation to knowledge production, while privileging Aboriginality among those doing the examining. Working in partnership with Aboriginal 
people and their communities gives a richer understanding of the research needed and the nuanced Aboriginal cultural protocols to be considered (Tachine, 2018).

The engagement of Aboriginal ways of "doing" within universities enhances the quality of research projects and reduces potential negative effects for Aboriginal people. Buoyed by this "knowing," moving beyond research "reference groups" to adopt holistic ways to engage accountable practices that rely on Aboriginal knowledges becomes imperative. It brings the outsiders in and invites the insiders out. It promises opportunities for Aboriginal people to find safe spaces as both researchers and the researched. Research projects engaging emerging Aboriginal researchers or peoples must adopt significant cultural support mechanisms and engage cultural mentors to truly succeed. For example, a seemingly straightforward requirement in research is to undertake a literature review. Non-Aboriginal supervisors must acknowledge such a task will expose Aboriginal researchers to a litany of negative assessments of their knowing, being. and doing. However supportive the relationship between non-Aboriginal supervisors and Aboriginal researchers, a shared "being" with Aboriginal people trusted by the researcher are essential to guide their emergence from research work unscathed.

It is not enough to ask an emerging Aboriginal researcher if they are satisfied with support provided by non-Aboriginal supervisors. The "outsider" positioning identified in butjin makes power dynamics visible. While feelings of not yet belonging to universities are not exclusive to emerging Aboriginal researchers, unresolved colonising histories contribute to our experiences as outsiders and the ways power dynamics affect us differently. Responding to power dynamics between non-Aboriginal supervisors and emerging Aboriginal researchers requires Aboriginal people to populate our research 
journeys, whether sourced inside or outside academic institutions. Non-Aboriginal supervisors are uniquely positioned to produce sweeping systemic change by asking emerging Aboriginal researchers "who might help" rather than "if" Aboriginal people are needed as mentors, supervisors, or panellists (Trudgett, 2014).

The concepts surrounding the insider-outsider exemplar for Aboriginal people is multifaceted and contains levels of connectivity and relatedness, respect for Elder knowledge, and individual journeying for those reawakening what lives within our being. It also acknowledges the power of our voices, our world, our stories, and our ancestors by recognising their footsteps when undertaking research within university spaces.

The recognition of the cultural interface, the overlapping realm that exists between university systems and Aboriginal ways of knowing, doing, and being initiates knowledge and learning experiences. Here within the cultural interface, ngarrangga (deep listening) resides, a crucial element for hearing stories, changing, and Indigenising the academy. Through the telling of stories, bringing strands of experience into the weave, we have created a carrier to take forth our understandings, not as an end but an invitation to craft and expand on the stories told, and relationships, experience, and knowledge gained. 


\section{Figure 7}

Butjin Djuyal (Story Basket)

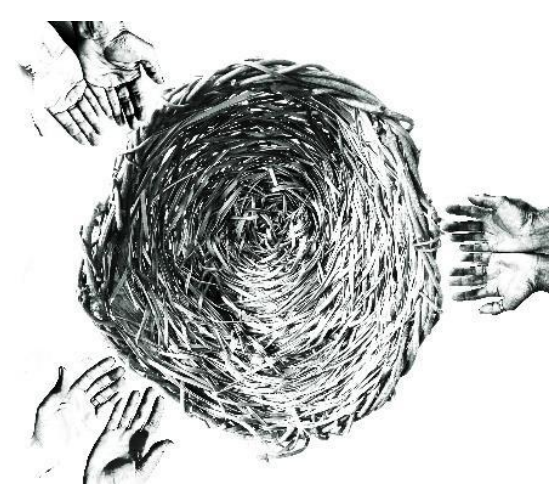

Note: Photographs supplied by Anjilkurri, Tess, and Kylie, image produced by Anjilkurri Radley

As the ends of the grasses are now in place to secure our weave, we view all the strands woven to form butjin. As Master Weaver, Birrbay woman, Patricia McInherny teaches us, "no weave can't be mended and there is always the ability to extend and reshape the butjin" (personal communication, March 7, 2020). Hence our stories can change and there are other stories to be told to enhance, expand, and strengthen butjin. As the djiyagan gift the butjin (see Figure 7) to you, we close our weaving circle with a blessing.

Wakulda nyiirun ngarrangga (Let us all listen as one) 


\begin{tabular}{|c|c|}
\hline \multicolumn{2}{|c|}{ Glossary of Words and Phrases, Gathang Language } \\
\hline Baan & Aunty, Elder \\
\hline barray & the land \\
\hline bila yii maraliyn & river is flowing \\
\hline bubaliyn & sleeping \\
\hline butjin & basket, carry vessel \\
\hline butjin djuyal & story basket \\
\hline djinangga yuungga & insider-outsider \\
\hline djiyagan & sister/s \\
\hline djiyagan dyuyaliyn djuyal & sisters telling stories \\
\hline dyuyaliyn & talking \\
\hline ganggali garral djuyalgu & weaving story \\
\hline matjarr djuyal & hand talk \\
\hline minya djuyal & this is the story \\
\hline mitji djiyagan & little sisters \\
\hline ngaluwi & wave (tidal) \\
\hline ngarralbaa & learning place \\
\hline ngarrangga & must listen \\
\hline ngarrayn & learning \\
\hline nyiirun ngarrangga & we all must listen \\
\hline wakulda & as one \\
\hline wakulda yabang mayan.gu & a way forward as one \\
\hline wati & tree, stick \\
\hline wati bunggil & clapping sticks \\
\hline wiyagi Gathang & a call to language \\
\hline
\end{tabular}


wubal matjarru djinanggabirang weaving from the inside

wubul matjurru yuunggabirang weaving from the outside

wuruma the wind

yukulduwa ganggali garral weaving through heart

\section{About the Authors}

Anjilkurri (Rhonda) Radley is Birrbay/Dhanggati First Nation Australian and currently a $\mathrm{PhD}$ student at the Western Sydney University, NSW, Australia. As a leader in the revitisation of the Gathang Language, Anjilkurri research interests includes the usefulness of gesture to teach language and Indigenous pedagogy. anjilkurriconnections@hotmail.com

Dr Tess Ryan is a Birpai woman and $\mathrm{PhD}$ holder regarding Indigenous Australians women's leadership. She has held a postdoctoral position with The Poche Centre for Indigenous Health at The University of Melbourne. Dr Ryan currently holds an Indigenous curriculum development and research capability building role with The Australian Catholic University. tessryan71@outlook.com

Kylie Dowse is a Gamillaraay, First Nation Australian woman who lives on Birpai country (NSW, Australia) and works across Gumbaynggirr and Birpai lands (NSW, Australia) as a Narrative Therapist. Her work, and research with University of Melbourne, explore ways to bring forward strong stories of resistance so richly present among Aboriginal people. kylie.dowse@outlook.com 


\section{References}

Archibald, J. (Q'um Xiiem). (2008). Indigenous storywork: Educating the heart, mind, body and spirit. UBC Press.

Ash, A., Hooler, P., Williams, G., \& Walker, K. (2010). Maam ngawaala: Biindu ngaawa nyanggan bindaayili (Language centres: Keeping language strong). In J. Hobson, K. Lowe, S. Poetsch, \& M. Walsh (Eds.), Re-awakening languages: Theory and practice in the revitalisation of Australia's Indigenous languages (pp. 106-118). Sydney University Press.

Asmar, C., Page, S., \& Radloff, A. (2011). Dispelling myths: Indigenous students' engagement with university, AUSSE Research Briefings, v.10 April 2011.

Becker, S., Bryman, A., \& Ferguson, H. (2012). Understanding research for social policy and social work: Themes, methods and approaches. Policy Press.

Bonner, A., \& Tolhurst, G. (2002). Insider-outsider perspectives of participant observation. Nurse Researcher 9(4), 7-19.

http://doi.org/10.7748/nr2002.07.9.4.7.c6194

Chew, K.A.B. (2019). Weaving words: Conceptualizing language reclamation through a culturally-significant metaphor. Canadian Journal of Native Education, 41(1).

Denborough, D., (2008). Collective narrative practice: Responding to individuals, groups, and communities who have experienced trauma. Dulwich Centre Publications.

Evered, R. \& Louis, M. R. (1981). Alternative perspectives in the organizational sciences: "Inquiry from the inside" and "inquiry from the outside." Academy of Management Review, 6, 385-395.

Ewen, S., Ryan, T., \& Platania-Phung, C. (2019). Further strengthening research capabilities: A review and analysis of the Aboriginal and Torres. Lowitja Institute.

Fredericks, B., Mills, K., \& White, N. (2014). "I now know I can do this now": Indigenous women and writing in the Australian higher education sector. Journal of Writing and Writing Programs, 18(1), 1-11.

Goldin-Meadow, S. (2014). Widening the lens: What the manual modality reveals about language, learning and cognition. Philosophical Transactions of the Royal Society B: Biological Sciences, 1-11.

Gullberg, M. (2014). Gestures and second language acquisition. In C. Müller, A. Cienki, E. Fricke, S. Ladewig, D. McNeill, \& S. Tessendorf (Eds.), Handbook of linguistics and communication science. Body-language-communication: An international handbook on multimodality in human interaction. (pp. 1868-1875). Mouton de Gruyter. https://doi.org/10.1515/9783110302028.1868 
Henderson, M. B. J. Y., \& Battiste, J. (2002). Protecting Indigenous knowledge and heritage. Purich Publishing Ltd.

Hobson, J., Oakley, K., Jarrett, M., Jackson, M., \& Wilcock, N. (2018). Bridging the gap in Indigenous Australian languages teacher education. In P. Whitinui, C. Rodríguez de France, \& O. McIvor (Eds.), Promising practices in Indigenous teacher education (pp. 105-118). Springer.

Kovach, M. (2009). Indigenous methodologies: Characteristics, conversations, and contexts. University of Toronto Press.

Lissarrague, A. (2010). A grammar and dictionary of Gathang: The language of the Birrbay, Guringay and Warrimay. Ligare Pty Ltd.

Macedonia, M., \& von Kriegstein, K. (2012). Gestures enhance foreign language learning. Biolinguists, 6 (3-4), 393-416.

Martin, K., \& Mirraboopa, B. (2003). Ways of knowing, being and doing: A theoretical framework and methods for Indigenous and Indigenist re-search. Journal of Australian Studies, 27(76), 203-214.

Martin, K. (2006). Please knock before you enter: an investigation of how rainforest Aboriginal people regulate outsiders and the implications for western research and Researchers (Doctoral dissertation, James Cook University).

Myerhoff, B. (2007). Stories as equipment for living: Last talks and tales of Barbara Myerhoff. (M. Kaminsky, M. Weiss, \& D. Metzger, Eds.). University of Michigan Press.

Nakata, M. (2017). An Indigenous standpoint theory. In Disciplining the savages: Savaging the disciplines. Aboriginal Studies Press.

Newel, M. (Director). (2019). In my blood it runs [Film]. Producers Newel, M., Behrendt, L., Naninaaq Edwardson, R. \& Hyde, S. https://inmyblooditruns.com/

Pike, K. L. (1954). Emic and etic standpoints for the description of behavior language in relation to unified theory of the structure of human behavior. Mouton.

Power, D. (2013). Australian deaf people and Aboriginal sign language. Sign Language Studies. 13(2), 264-277.

Radley, A., Jones, C., Hanham, J., \& Richards, M. (2021) Matjarr Djuyal: How using gesture in teaching the Gathang helps preschoolers learn nouns. Languages, 6(2) 103. https://doi.org/10.3390/languages6020103

Randall, B. (2006). The Land Owns Us. Director Hogan, M. Producer, Randall, B., Hogan, M. https://www.youtube.com/watch?v=w0sWIVR1hXw\&t=17s 
Smith, L. T. (1999). Decolonizing methodologies: Research and Indigenous people. University of Otago Press. http://www.slideshare.net/drjayeshpatidar/experimental-research-design$\underline{20769996}$

Smith, L. T. (2012). Decolonizing methodologies: Research and Indigenous peoples (2nd ed.) Zed Books.

Tachine, A. R. (2018). Story rug: Weaving stories into research. In R. S. Minthorn, \& H. J. Shotton (Eds.), Reclaiming Indigenous research in higher education (pp. 64-75). Rutgers University Press. http://doi.org/10.2307/j.ctt1v2xw7v

Trudgett, M. (2014). Supervision provided to Indigenous Australian doctoral students: A black and white issue. Higher Education Research \& Development, 33 (5) 10351048. http://dx.doi.org/10.1080/07294360.2014.890576

Tuck, E. (2009). Suspending damage: A letter to communities. Harvard Educational Review, 79(3), 409-427.

Tuck, E. \& Yang, K. W. (2012). Decolonization is not a metaphor: Decolonization: Indigeneity, Education \& Society, 1(1), 1-40.

Ungunmerr-Baumann, M. R. (1988). Dadirri, Inner deep listening and quiet still awareness. A reflection by Miriam-Rose Ungunmerr. https://www.miriamrosefoundation.org.au/dadirri/

Wingard, B. \& Lester, J. (2001). Introduction. Telling our stories in ways that make us stronger (pp. v-vii). Dulwich Centre Publications.

Yunkaporta, T. (2009). Aboriginal pedagogies at the cultural interface. [Doctoral dissertation, James Cook University]. http://eprints.jcu.edu.au/10974/ 